\title{
Trust And Sincerity in Art
}

\author{
C. THI NGUYEN \\ University of Utah
}

\begin{abstract}
Our life with art is suffused with trust. We don't just trust one another's aesthetic testimony; we trust one another's aesthetic actions. Audiences trust artists to have made it worth their while; artists trust audiences to put in the effort. Without trust, audiences would have little reason to put in the effort to understand difficult and unfamiliar art. I offer a theory of aesthetic trust, which highlights the importance of trust in aesthetic sincerity. We trust in another's aesthetic sincerity when we rely on them to fulfill their commitments to act for aesthetic reasons - rather than for, say, financial, social, or political reasons. We feel most thoroughly betrayed by an artist, not when they make bad art, but when they sell out. This teaches us something about the nature of trust in general. According to many standard theories, trust involves taking the trusted to be cooperative or good-natured. But trust in aesthetic sincerity is different. We trust artists to be true to their own aesthetic sensibility, which might involve selfishly ignoring their audience's needs. Why do we care so much about an artist's sincerity, rather than merely trusting them to make good art? We emphasize sincerity when wish to encourage originality, rather than demanding success along predictable lines. And we ask for sincerity when our goal is to discover a shared sensibility. In moral life, we often try to force convergence through coordinated effort. But in aesthetic life, we often hope for the lovely discovery that our sensibilities were similar all along. And for that we need to ask for sincerity, rather than overt coordination.
\end{abstract}

$\mathrm{H}$ ERE are some feelings I have about Kanye West's music and its reception. Through Life of Pablo, his albums grew more difficult and more alienating. After some time and effort, however, I came to find each one deeply rewarding. But as his work became harsher and more structurally bewildering, each album took me longer to come to terms with. I pressed on through those early difficult listens because, by that point, I had come to trust in West as a musical artist.

Contact: C. Thi Nguyen <thi.nguyen@gmail.com> 
Other people tuned out as West's work evolved. They had deeply loved his earlier work, but were unwilling to invest energy in the attempt to come to terms with his later work. I have feelings about them, too: I think they are doing something ever-so-slightly wrong. It's not just that they are missing out on a bit of extra pleasure. It's that they are failing to offer West the kind of trust that he deserves, given their prior relationship to his work. And then there are people who never gave West's music a chance. Some of these people are my friends and fellow appreciators, with whom I have a long history of listening together and appreciating things together-a history of shared sensibility. When such aesthetic compatriots refuse to even try to listen with an open mind despite my gushing - and despite massed critical consensus ${ }^{1}-\mathrm{I}$ feel that they are failing to trust when they should.

And we can feel betrayed towards artists, too. The consensus among fans and critics seems to be that West's most recent album ye was tossed off without much real effort. Longtime West listeners felt deeply let down by the album and by the artist behind it, if the online outpouring was any judge. Music critic Meaghen Geavey writes:

We have reached the point where West's once-constant churn of ideasusually inspired, regularly awkward, but always like nothing else out there-is barely meeting the standard of "Lift Yourself," the desperate troll banger that preceded ye, corralling every meaning of the word "scat." The problem with ye is not that it was made by an unrepentant asshole, but that it is thoroughly, exhaustingly boring-a word I never imagined would apply to a generation's most reliable innovator. ... ye feels rickety, almost, as if removing a bassline would send the whole thing toppling. ... It's as if he'd completely forgotten the music was the reason we loved him in the first place. ... [In "Ghost Town"] He gargles a few half-finished thoughts, his tone not so much sad as dazed, re-using the verse melody from "Runaway" over a sample chop that, at one point, sounds a whole lot like his work with Jay-Z. ... It's an ode to total numbness, and somehow it's also ye's emotional climax, an irony as apt as it is depressing. ${ }^{2}$

1. Aaron Meskin pointed out, in personal communication, that, in the Village Voice Pazz \& Jop meta-poll, the two most critically lauded artists over the history of the meta-poll are Bob Dylan and Kanye West. Note that I am not claiming here that one should adopt an aesthetic judgment merely on the say-so of another. I am suggesting only that we might try to appreciate something based on the testimony of another (Nguyen 2017a; 2019).

2. https://pitchfork.com/reviews/albums/kanye-west-ye/ 
What unites these various responses is the presence of trust and its kin. Richard Holton notes that there are characteristic normatively-laden attitudes which surround trust:

When you trust someone to do something, you rely on them to do it, and you regard that reliance in a certain way; you have a readiness to feel betrayal should it be disappointed, and gratitude should it be upheld. (Holton 1994: 67)

And, in aesthetic life, we are not simply surprised when an artist lets us down; we can feel betrayed. When somebody mistrusts our recommendations when we think we have earned their trust, we are hurt. When I discover some hidden perfect subtlety, buried deep in the innards of some labyrinthine novel, I feel gratitude that the author had trusted their audience enough to place it there.

But the role of trust in art-in our relationships to artists, audiences, critics, and fellow appreciators - has been relatively under-explored, at least in philosophical aesthetics. Philosophers of art have focused their attentions on one very specific kind of trust: the sort involved in the acquisition of aesthetic knowledge via testimony. They have debated, at great length, whether and why there is really a problem with acquiring aesthetic judgment strictly through testimony. ${ }^{3}$ But there are many other kinds of aesthetic trust. Artists create subtle, complex works, trusting their audiences to discover those works' more esoteric qualities. Audiences invest their time and energy in those works, trusting artists to have created with dedication and sincerity. Museum-goers trust curators to choose aesthetically profound works and not just aim to maximize ticket sales. Actors trust their directors; classical musicians trust their conductors. Painters trust manufacturers to be meticulous in making pigments and paper. Readers trust critics to get at the heart of an artwork, instead of just saying clever stuff to advance their careers.

In this paper, I explore the central role of trust in our lives with art. I will start by considering one particular role for trust. Trust makes it possible for us to aesthetically change and grow, by giving us reasons to approach new and unfamiliar art. Without trust, audiences would have little reason to put in the effort to understand inherently difficult art, and artists would have little reason to hope that audiences would rise to the challenge.

There are, I claim, many forms of trust in aesthetic life, including trust in each other's aesthetic competence and in each other's steadfastness to a style or a

3. For starters, see Hopkins (2001; 2011), Budd (2003), Livingston (2003), Meskin (2004; 2007), Laetz (2008), Whiting (2015), Robson (2015), Lord (2016), McKinnon (2017), Ransom (2017), and Nguyen (2017a; 2019). 
sensibility. But I will highlight a form of trust that seems especially characteristic of much contemporary aesthetic life: trust in aesthetic sincerity. In much current aesthetic practice, we typically trust one another to act from aesthetic considerations, rather than financial, social, or other non-aesthetic considerations. Suppose an artist makes a wild stylistic shift-a bold artistic experiment, following their own aesthetic sensibility - and it turns out terribly. They have failed to make good art, but they have succeeded in being aesthetically sincere. And our greatest ire is often directed, not at the artist that makes bad art, but at the insincere artist - the sellout.

My goals here are two-fold. First, I hope to show that our understanding of our art practices will benefit from thinking carefully about aesthetic trust. Second, I hope to expand our understanding of trust in general. Much of the recent discussion of the normative dimension of trust emerges from analyses of moral scenarios. But there is more to life than morality. ${ }^{4}$ Thinking about aesthetic life will help deepen our understanding of the varied forms of trust. Trust in aesthetic sincerity, it turns out, has a special character - one that is quite distinctive from the way we trust in the moral and epistemic spheres. I suggest that this is because of our distinctive goals in aesthetic life. We ask for sincerity, rather than kindliness, cooperativeness, or reliability, because we are trying to nurture creativity and originality, and because we are hoping to encourage a very particular form of shared experience.

\section{The Motivational Problem of Difficult Art}

Appreciating art requires investment. It requires, at the very least, time and energy. It usually also takes willpower, focus, and emotional resources. Experiencing art can be risky, too. Opening yourself to an artwork can leave you emotionally vulnerable. You can expose yourself to psychic harm from manipulative or abusive art.

Many of these concepts - openness, vulnerability, emotional risk-are fairly alien to modern aesthetics, and would require significant work to render into philosophically legible terms. Let's start, then, with a more minimal observation: that some art requires a significant investment of resources before its value is adequately revealed. Some works seems impenetrable, at first. It takes some devoted effort to apprehend their structure - to detect their subtle beauty, or to make sense out of the seeming chaos. Call something difficult art if it requires

4. I owe this way of framing the issue to Jonathan Gingerich. This paper will focus on the contrast between aesthetic trust and moral trust, focusing on the normative dimension. There is another literature, on the epistemology of trust and testimony, that is a bit further afield. I have discussed the relationship between trust in aesthetic and epistemic testimony in Nguyen (2019). 
a significant investment of mental, emotional, and other personal resources to access its value, and if there is relatively little direct sign of its value early in the appreciative process. ${ }^{5}$ Difficulty can be relative. Some art is difficult for us simply because we lack the appropriate familiarity and experience. When we are raised in one tradition, and then confront work from an alien tradition, we often lack the skills to find the value in it on a first pass - or a second, or a fifth. On the other hand, some art is inherently difficult: like the oblique density and texture of Marianne Moore's poetry, or John Coltrane's dense late experiments with free jazz, or Joanna Newsom's Milk-Eyed Mender, so full of crackling, but expressive, aural discomforts.

What reasons could a potential appreciator have to try and get over those early roadblocks? On first encounter, it can be hard to tell difficult art from bad art. To the uninitiated, Coltrane's later work, and much of the free jazz which follows, is indistinguishable from random noise. Many can see no difference between abstract expressionist paintings and the random splattering of a child. And some forms of difficulty are subtle. The difficulty itself can be invisible to the careless eye. Audiences raised on Western modernist poetry, for example, often miss the quality of Basho's minimalist haiku and Tu Fu's plain-spoken verse. These poems' superficial clarity masks their artistic depth. The verse can seem simpleminded and childish to those raised on the more willfully obscure poetry of, say, John Berryman and Jorie Graham. Similarly, to those unversed in the complexities of hip-hop production, it's easy to mistake Kanye West's deliberately rough vocal work for mere ineptness-and miss the complex relationship between the simplistic vocal work and the dense, atmospheric production work in which it is embedded.

One can hear that aesthetic difficulty implied in the dismissals of many a detractor, who mock abstract painting and free jazz for being so much random gibberish. To the initiated, it is clear what's going on here: the detractor hasn't put in the work to get over the difficulty hump, and so does not yet see what there is to be seen. More importantly, they mistake their own insensitivity for a lack of quality in the work itself. They see nothing, and take that as a sign that there is nothing to be seen. To somebody who sees how good the art is, this dismissive attitude might seem like pure arrogance. But something more complicated is going on. The detractor's position is actually quite reasonable, up to a point. After all, we are limited beings, who cannot expend energy willy-nilly. We usually only spend aesthetic attention where we have good reason to think that our investment will yield good returns. And the value of difficult works is,

5. I do not claim that this tracks the natural use of the term "difficult art". It is a stipulative definition for the sake of brevity. The discussion of difficult art in this paper owes a significant debt to conversations with Matt Strohl. 
by nature, veiled. Difficult works present us, then, with a motivational puzzle. If their value is not apparent on their face, what could motivate somebody who does not yet see, to put in the effort to see? In a world with such an overwhelming amount of art, how can we tell the bad from the as-yet-uncomprehended?

Since the uninitiated cannot perceive the potential value of a difficult work for themselves, their reasons for spending effort in pursuit of that value cannot come from their appraisal of the work itself. ${ }^{6}$ The reasons can come, however, from the social context of the work. We can expend effort on difficult art because somebody we trust tells us to. Such trust is crucial for our personal development as appreciators. How else could we expand into new genres, could we grow out of our early narrow aesthetic channels? How else would we know where to look? Trust can provide reasons for us to get past the apparent surface valuelessness or incomprehensibility of a work.7 Thus, trust underwrites the expansion of our aesthetic sensibilities. This is not to say that there could never be any difficult art without trust. But in order to make a regular and reliable practice out of inherently difficult art, we need trust. Trust enables audiences to locate worthwhile difficult art. And trust gives social assurances to artists who make difficult art, since they can rely on their audiences spending the energy to find and apprehend their art.

We now have a diagnosis of the person who dismisses, at a first glance, difficult works as obviously worthless, and who stays firm on their early negative judgment-even in the face of the praise from trustworthy sources. Theirs is not a problem of brute insensitivity or arrogance towards the artworks themselves. After all, we need a positive reason to put in the extra effort with difficult art, and difficult art will not provide the uninitiated with that reason directly. It's the social matrix surrounding the art that lets us surmount the motivational problem. The problem with the dogmatically dismissive person, then, lies not in their brute insensitivity to art itself, but in their refusal to trust where they should. Such a person trusts their own quick reaction that, say, all rap is musically worthless over the assurances of another sensitive soul who says that there are riches to be found there. Such a person is unwilling to admit that their own quick judgment might admit of lacunae. The dismisser here is a peculiar kind

6. Notice that some work has an easy surface, which invites the appreciator in, so that they might spend enough time to appreciate the work's more difficult parts. That is certainly a strategy - and one worth investigating elsewhere-but, by my definition, such things do not count as "difficult works". Importantly, work from alien traditions typically appears to the uninitiated as difficult through and through.

7. Sherri Irvin (2007) makes a somewhat similar point in her discussion of the harms of forgery. She suggests that we need to trust others to further our aesthetic understanding. Our two discussions concern different functions of trust, though I believe them to be compatible. My claim here concerns the identification of valuable works, and hers concerns how trust provides new data points from which we can construct new aesthetic understandings. 
of aesthetic solipsist, who is unwilling to admit the possibility that others might possess aesthetic sensitivities which the solipsist themselves might lack. ${ }^{8}$

Notice, too, that we trust not only recommenders, but also artists, communities, and styles. I pay attention to Coltrane's later work because I love his earlier work and I trust him not to be wasting my time. I push through the seeming incomprehensibility of Ornette Coleman's free jazz because, in part, I know that Coltrane admired Coleman's music. I trust curators that these wild splotches of abstract expressionist paint are worth poring over. And I trust certain communities as a whole, like the New York jazz scene and or the Atlanta trap sceneenough to be willing to spend at least a bit of attention on any artist who emerges from those scenes.

Thinking in terms of trust will help us to chart the social practices involved with the art world. It can help bring to light how certain key pitfalls and traps of trust can recur in the world of art. Consider, for example, the potential for dangerous social feedback loops in our aesthetic search procedure. Often, we put in the effort to understand some new piece of difficult art because some trusted expert recommended it. But how did we come to trust that expert in the first place? Typically, we pick experts by applying our own capacities of aesthetic judgment and our own background beliefs about what's worth paying attention to. We trust those experts whose tastes we recognize, in part through their consonance with, and demonstrated capacity to extend, our own tastes. But this threatens us with the possibility of a vicious circle of trust-one whose pattern should be familiar from other domains. We are threatened here by the possibility of an aesthetic echo chamber. I might select experts based on my narrow tastes, and arrive at a set of experts who echo my own narrowness. Those experts might give me reason only to further develop my aesthetic skills within that thin band. Imagine, for instance, that I had been raised in a tradition of classical European music, and then encountered a distinct, difficult form of music from a tradition with which I was unfamiliar-say a difficult work of hip hop. The aesthetic qualities of hip hop require a completely different mode of listening and attention. The listener must develop a different set of sensitivities and skills. Here's the danger: I might not recognize the aesthetic quality of the hip hop for myself. At the same time, I might also fail to trust the appropriate experts to guide me through hip hop and help me to develop my hip hop listening skills. The structure of my social network might leave me with no motivational traction on hip hop.

8. My claim here is not that one should defer to the judgments of aesthetic experts, but that one should let the contrary judgments of experts give one a reason to look again. For more on this topic, see Cross (2017) and Nguyen (2017a; 2019). 
Much depends, however, on the topology of my social network. If my network contains many individuals who care about both classical and hip hop, I can avoid this aesthetic echo chamber. If, on the other hand, the worlds of classical music and hip hop are segregated, I will tend to identify as experts those whose interests are also narrowly spent on classical music. Using my network of trusted experts will likely only reinforce my belief in the superiority of classical music. Over time, trust in my curated set of experts will direct me to spend more attention on classical music, which will further refine my appreciative skills for that music. This will create a comprehensibility gap between the familiar and the unfamiliar, accompanied by a coverage gap in my network of trust networks. When looking into unfamiliar music traditions, difficult music is indistinguishable from bad music. So, lacking the right trust network, I won't be presented with the right reasons to push me past my initial uncomprehending impressions of hip hop. ${ }^{9}$ This possibility is heightened if the comprehensibility gap falls along the same lines as credence gaps between different social groups, such as the unjust credence gap between racial groups (Fricker 2007).

\section{Why Trust?}

There are two questions we might now ask. First, why is trust the right concept for thinking about our aesthetic choices? Why not think, instead, that we were simply predicting future aesthetic success based on inference from past success? Perhaps we are simply inferring from the greatness of the last few Cardi $\mathrm{B}$ albums that the new album will also be fantastic. Second, even if we really are trusting each other in aesthetic life, should we be? Let's spend some time with the simpler descriptive question before we turn to the justificatory question.

Trust sits at a complex nexus of distinctively normative concepts. As Annette Baier says, when we trust, we make ourselves vulnerable. In Baier's account, to trust is to depend on the good will of another (Baier 1986: 234-35). Furthermore, trust comes packaged with some specific kinds of affective response. When a trusted person lets us down, we do not simply revise our expectations to match. We feel betrayed; we think the trusted person deserves condemnation. And sometimes we are hurt when another fails to trust us as much as we deserve. On a first pass, these affective phenomena seem to indicate that trust is pervasive

9. This account of vicious circles of trust draws from my analysis of expert trust loops in aesthetic and moral testimony, and my discussion of echo chambers as trust manipulators. See Nguyen $(2020 ; 2018)$ for an in-depth analysis. My own thinking about echo chambers actually began, not with political cases, but with aesthetic cases like these. For an account of acquiring trust from experts by calibrating via agreement, see Philip Kitcher's (1993: 320-23) account of scientific trust. The notion of coverage gap draws from Sanford Goldberg's (2010: 154-84) discussion of coverage reliability. 
throughout our life with art. Fans feel betrayed by their beloved artist's selling out; museum-goers would feel betrayed if the curator's selections turned out to be paid product placements. And we can feel betrayed by artistic failures of a certain register. For example, music critic Jordan Sargent writes of West's ye:

Kanye used to justify such flights of imagination, his albums obsessively dissected, ranked, and considered in the grand pantheon of human artistic achievement. ye makes expending that sort of mental energy seem incredibly silly. Let us never speak of it again. ${ }^{10}$

Importantly, we trust each other over all sorts of things. Trust is not just about accepting others' testimony. We trust each other not only to speak truly, but to act well. We trust people to fix our cars, to look after our investments, and to stop us from doing something stupid after we've had too much to drink. So, too, many of our aesthetic relationships involve, not just trusting one another's aesthetic testimony, but trusting one another's aesthetic actions. We trust artists to create sincerely; we trust curators to display worthwhile art. We trust curators to direct our time and energy down worthwhile paths. We trust teachers with the development of our aesthetic sensibilities.

It will help here to make use of the recent philosophical literature on trust. ${ }^{11}$ Trust, in the standard accounting, is a three part relationship. There is a truster, a trusted, and an entrusted act or domain. I trust my banker with my money; I trust a teacher with my child's education and life. Baier suggests, however, that the colloquial use of the term "trust" indicates two possible sorts of attitudes. The first is one of simple reliance. Reliance is an attitude we can take towards ordinary objects. We rely on the shelf to hold up our books; we rely on our car to run. Reliance is an attitude of simple expectation. We rely on something to do some act based on our mere prediction that it will do so.

Reliance, by itself, isn't normatively loaded. I don't blame the shelf when it fails to hold up my book, nor do I feel betrayed when it collapses. I may feel disappointed, but the shelf's failure does not evoke from me the more accusatory attitude of betrayal. But there is a different form of trust-a richer, more normatively loaded trust-which we sometimes hold towards persons and person-like institutions. ${ }^{12}$ It is this richer form of trust that gives rise to a wider

10. https://www.spin.com/2018/o6/kanye-west-ye-review/. For the record, I enjoyed ye decently enough, and felt no betrayal myself-though I do not think it rises the heights of $M y$ Beautiful Dark Twisted Fantasy, Yeezus, or my own favorite, The Life of Pablo.

11. The summary which follows draws from Baier (1986), Holton (1994), Jones (1996), O'Neill (2002), Jones (2012), and Simpson (2018). Particularly useful summaries of the recent trust literature can be found in Simpson (2012) and Hawley (2014).

12. Elsewhere, I have objected to the anthropocentric focus of the trust discussion, and attempted to offer an expanded theory of trust which can make sense of trust and betrayal towards 
variety of complex affective responses; it puts us in the world of praise, blame, and betrayal. Though I had relied on the shelf, I don't blame it for failing. However, if Ikea had implied that the shelf could bear such a load, I might reasonably blame Ikea. This reveals that where I had only relied on the bookshelf, I had richly trusted Ikea.

Following the standard usage in the recent academic literature (and departing from looser colloquial usage), I will use "reliance" to refer to the thinner, merely predictive attitude, and "trust" to refer to the richer, more normatively loaded attitude. On most accounts, trust is analyzed as reliance plus something extra. When I trust you, I rely on you, but I also hold some further normative attitude towards that reliance. We can, then, sort between cases of trust and reliance by looking at the negative reactions evoked by their failure. As Katherine Hawley puts it, when something fails to live up to our mere reliance, we are only disappointed. When somebody fails to live up to our trust, we feel betrayed (Hawley 2014: 3).

Notice that our attitudes towards people can also vary between trust and reliance. If I regularly see you exiting the building exactly at $5 \mathrm{PM}$ and come to use your departure to time my own exit, I am merely relying on you. I ought not feel betrayed if you suddenly change your schedule. If, in the other hand, you had promised to knock on my door at 5 PM to remind me to get going, then I can blame you if you don't. Trust can arise implicitly, through our taking on parts and roles in some cooperative endeavor. Suppose we have built a life together and evolved a system where one of us makes breakfast while the other makes coffee and walks the dog. We each know that the other depends on us to take care of our morning's share. Even though we have never exchanged promises or signed contracts, we surely have come to trust each other.

What might ground that reaction of betrayal? In an early and influential account, Baier suggests that to trust somebody is to rely on their goodwill towards you (Baier 1986: 234-36). The betrayal, then, amounts to discovering that they lack goodwill. As appealing as it might seem, however, the goodwill account admits of significant counterexamples. Onora $\mathrm{O}^{\prime} \mathrm{Neill}$ points out that I may trust a doctor without thinking they bear me any goodwill. They may be irritated by me and have no particular positive feeling towards me, but they have taken an oath to care for their patients, and I depend on them to fulfill that oath (O'Neill 2002: 14). Professionalism, then, sometimes can serve as an adequate substitute for goodwill, as grounds for trust. And, as Hawley

objects (Nguyen in press). Since I know this to be a highly controversial view, I have avoided relying on this expanded theory of trust in this paper, and sought to make my discussion here compatible with more widely accepted accountings of trust. Those convinced by that expanded theory should treat the present paper as an analysis of a particular sub-type of trust: that of interpersonal, commitment-based trust. 
says, sometimes we don't want to enter into relationships of trust, even when it is apparent that goodwill is involved. I may be willing to cook dinner most nights for my spouse, and I may do it out of goodwill, but I don't want my spouse to come to trust me to cook dinner. I may wish to preserve for myself the right to withdraw from that practice without incurring blame (Hawley 2014: 7).

Of the various candidate theories of trust in the running, I find Hawley's positive account the most convincing. It is crucial, says Hawley, that there are three distinct attitudes of trust we can take towards others. We can actively trust them or actively distrust them-but we can also simply refrain from trust or distrust. I trust my partner to care for me. I distrust this scumbag politician's promises. But my attitude towards my next-door neighbor's cooking is neither active trust nor active distrust: it is non-trust. It's not the case that I trust them to bring me food, but it's not the case that I distrust them, either. Our relationship has not yet entered into the domain of trust and distrust.

Most standing theories of trust cannot account for this tripartite distinction. For example, traditional goodwill accounts of trust-that treat trust as simply a belief in another's goodwill-can capture only two states: trust or distrust. To solve this problem, Hawley offers the following account:

To trust someone to do something is to believe that she has a commitment to doing it, and to rely upon her to meet that commitment. To distrust someone to do something is to believe that she has a commitment to doing it, and yet not rely upon her to meet that commitment. (Hawley 2014: 10)

The commitment account neatly explains the difference between trust, distrust and non-trust. When I trust somebody, I take them to have made a commitment and I rely on it. When I distrust somebody, I take them to have made a commitment, yet expect them to fail to meet that commitment. And when I have an attitude of non-trust, I do not believe that they have made a commitment at all. This account also explains how one can trust wrongly. Trusting somebody involves believing that they have made a commitment. If I trust you to do something, and you've actually made no commitment to do it, then it would be wrong of me to hold you to that unmade commitment or to reproach you for failing to fulfill it. ${ }^{13}$

As Hawley says, in order for this to be a plausible account, we must hold to a very loose notion of commitment. Commitments, she says, can be explicit

13. I won't rehearse the reasons for thinking Hawley's view is superior to the available candidates; her own defense is, to my mind, quite satisfying. 
or implicit; they can be weighty or trivial. They can come through external circumstances or by taking up various social roles. Commitments can arise without any explicit promising, when we enter into practices of mutual dependences and expectations. Note that Hawley's account builds in skillfulness, too. I don't simply trust you to try. Trusting you involves relying on your actual ability to meet your commitments.

\section{Aesthetic Commitments}

Hawley's account, I think, gets us a long way towards understanding what's going on with the social relationships which surround and bolster our art practices. ${ }^{14}$ We do not simply rely on each other; we trust each other. In Hawley's terms, that means that we do not simply rely on each other's predictability; we rely on each other's commitments, and feel betrayed when those commitments aren't met. And we do feel betrayed in the aesthetic realm. I would feel betrayed if I found out, say, that David Simon chose the character arcs and character fates in The Wire based entirely on market research about which characters would sell the most action figures. ${ }^{15}$ Recall Hawley's suggestion that many of the commitments of trust arise, not through explicit promises, but from the roles we adopt. Many formal and informal roles within the art world - artist, curator, critic, appreciator, and even simply friendly interlocutor-seem to come packaged with a set of commitments. Such commitments seem part and parcel of our social practices of art-making and art consumption. ${ }^{16}$ Our response of aesthetic betrayal reveals that we take ourselves to be involved in the practice of making and receiving aesthetic commitments.

Let's look more closely at the nature of aesthetic trust. This will help me to explain why exactly I think that it is trust, rather than reliance, that is in operation here. First, consider the following different forms of aesthetic trust we might take up. (I take the following to be schemas for general classes; different particular instances can add to or modify these basic schemas in various ways.)

14. I don't necessarily think that Hawley's account is the complete account for all uses of the term "trust". Thomas Simpson (2012) may be right when he says that the term arises in many distinctive situations of the breakdown of cooperative activity, and that each different context leads to a different use of the term 'trust'. But I think Hawley's account clearly captures one use of the term which fits well with the use in the aesthetic context.

15. Obviously, Omar.

16. I mean "our" here in a fairly local way. The attitudes and practices I'm analyzing seem distinctive of relatively recent Western European art practice and its direct descendent. It seems perfectly plausible that other traditions of art practice would involve different sets of commitments. 


\section{Trust in aesthetic competence}

To trust in X's aesthetic competence is to rely on $X$ to meet their commitment to successfully bring about aesthetically valuable states of affairs (for some set of acts).

\section{Trust in aesthetic sincerity}

To trust in X's aesthetic sincerity is to rely on X to meet their commitment to act from aesthetic considerations (for some set of acts).

\section{Trust in aesthetic steadfastness}

To trust in X's aesthetic steadfastness is to rely on $X$ to act from their commitment to a specified aesthetic sensibility (for some set of acts). ${ }^{17}$

The "some set of acts" condition specifies that aesthetic trust is limited to some specific domain. My trust in West's aesthetic sincerity only covers his acts in the realm of music-making, music recommendation and the like. I have no expectation that West will act from strictly aesthetic considerations, say, in his banking, or even in other aesthetic fields, like his fashion.

These proposed forms of aesthetic trust are quite different. Trust in aesthetic competence is trust in another to actually do it well, aesthetically speaking. If I were to trust in a musician's aesthetic competence, I would rely on their commitment to make good music. If I were to trust in a movie reviewer's aesthetic competence, I would rely on their commitment to reliably recommend good movies. And trust in aesthetic competence is broken by aesthetic failure. If I had such trust for somebody, I would feel betrayed when they made bad music or recommended bad movies.

Trust in aesthetic sincerity, on the other hand, is trust that somebody will act guided by aesthetic considerations. Trust in aesthetic sincerity does not demand that the trusted succeed in their attempt. Such trust would not be broken by aesthetic failure, in and of itself. It would be broken by the trusted person's acting for the wrong sorts of reasons-say, by acting from financial considerations or

17. I am presuming, for the sake of brevity, that aesthetic considerations, values, and sensibilities are central to art. Some might claim a broader set of characteristics for art. For example, one might think that the realm of art includes aesthetic considerations (such as beauty and grace) and artistic considerations (such as originality and creativity). In that case one could mirror my proposed various definitions of 'aesthetic trust' with a parallel account of 'artistic trust', and what I say would apply to both. 
considerations of social status. Notice how different trust in sincerity is from trust in competence. If a musician makes a bold experiment, guided by their own aesthetic sensibility, and fails utterly - if they follow their artistic muse off a cliff - this would be a failure of aesthetic competence, but not of aesthetic sincerity. Trust in sincerity is broken by the aesthetic sellout, not the aesthetic failure.

Finally, trust in aesthetic steadfastness is trust in somebody to stay the course. A member of a traditional folk music scene might have such trust for their fellows to continue making and caring about music in that style. ${ }^{18}$ Notice, though, how different the demand for steadfastness is from the demand for sincerity. Imagine, for instance, that our traditional folk musician fell in love with drum machines and hip hop sampling and changed musical direction. That could be a violation of steadfastness, but not of sincerity. Similarly, if that musician's work became more listless and tired, but remained within the aesthetic sensibility to which they had committed, they may have failed in their commitment to competence, but succeeded in their commitment to be steadfast.

Though these various aesthetic commitments can sometimes be made directly between individuals, in contemporary aesthetic life most aesthetic commitments seem role-based. We take up these commitments implicitly when we adopt certain roles, and these commitments are typically directed at others via their roles. The museum curator, in taking up their role, takes on certain aesthetic commitments to the museum's audience. The movie reviewer, in taking up their role, takes on certain commitments to their readership. We can detect the presence of those commitments by imagining how they might be betrayed - like if we found out that the curator was taking bribes, or if the movie reviewer was strategically condemning popular movies in order to go viral on Twitter. And we typically hold people to their commitments only when they are acting from within those roles. I expect a museum curator to recommend aesthetically valuable works when they are acting as a curator. When they praise their toddler's scribblings at home, they are clearly speaking not as a museum curator, but as a parent.

Why might these various forms of trust be so important in aesthetic life? Let's start with aesthetic competence. Trust in aesthetic competence is easy to explain; it solves the motivational problem of difficult art. Trusting in West's aesthetic competence will, by itself, give me reason to devote time and attention to his new album. When we trust in the competence of artists, reviewers, and curators, we will have guidance about where to spend our efforts, and reasons to broaden our tastes. Trust in, and commitment towards, aesthetic competence has a clear function in aesthetic life.

18. In Jennifer Lena's (2012) sociological typology of musical communities, the "traditionalist" community type is marked by its devotion to unchanging stylistic purity. 
But often, we seem even more invested in aesthetic sincerity. Though we can feel betrayal towards breaches of trust in aesthetic competence, our most vicious reactions are typically to betrayals of trust in aesthetic sincerity. We seem to feel more profoundly betrayed by the sellout than by the sincere failure. Suppose I find that West's new album tries to do far too many new things at once, collapsing under the weight of its own ambitions. It's a failure, but one that arises from a sincere attempt. I myself would react with only the mildest sense of betrayal-though I might feel quite disappointed. On the other hand, suppose I thought that the new album was oversimplified in a bid for commercial success. I would likely feel quite betrayed. I have some small degree of trust in West's aesthetic competence, but have, apparently, a much stronger and more normatively loaded trust in his aesthetic sincerity. And I take it that this pattern is a familiar one across many sectors of contemporary aesthetic life.

Obviously, all three forms of aesthetic trust can and do exist in certain specific contexts, in various and potentially overlapping ways. Different people make all sorts of commitments. A musician promises their manager that the next album will be amazing. When that manager stakes their credibility on that album's success, they are trusting in the musician's aesthetic competence. My childhood friends and I swear to each other that we will keep on loving the same seventies kung-fu flicks; we are trusting in each other's aesthetic steadfastness. Similarly, shared commitments to aesthetic steadfastness are characteristic of traditionalist musical communities, such as, say, the bluegrass preservationist community.

But, I claim, trust in aesthetic sincerity is particularly characteristic of contemporary aesthetic life. Aesthetic life shares, with other forms of life, trust in various forms of competence. But aesthetic life is often distinguished by an equal, and sometimes greater, degree of trust in sincerity. I will, in short order, attempt to offer an account of the functional importance of trust in aesthetic sincerity. Before I do, some clarifications of my account of aesthetic sincerity are in order.

First, what do I mean by "aesthetic considerations"? I can't hope to offer a complete rendering here, but there are enough obvious contrasts to get a first grip on the notion. When I buy a painting because I think it is beautiful or dramatic, I am acting from aesthetic considerations. When I buy it simply as a good investment, or because it is the right size and thickness to cover a hole in my wall, I am not acting from aesthetic considerations. ${ }^{19}$ I have left "aesthetic considerations" intentionally vague here, so that you may plug in your preferred account of aesthetic action and motivation. However, let me offer a sample plug-in, which will help flesh out how such an account might go.

19. I am consciously avoiding the question of what demarcates the aesthetic from the non-aesthetic. For a recent overview of those puzzles, as well as a clear statement of how and why one might punt on the issue, see Lopes (2019: 46-48). 
Dominic Lopes has offered the following notion of an aesthetic act. For Lopes, an aesthetic act is one that depends counterfactually on the actor's evaluation of aesthetic value (Lopes 2019: 32-36). That is, an act is aesthetic when the actor would have done something differently if they had a different evaluation of aesthetic value. A painter who paints a line just so because it will make the painting most aesthetically valuable is performing an aesthetic act, for if they had thought that some other line would have been aesthetically better, they would have painted that instead. A painter who puts the line just so just because paintings like this tend to sell well on eBay is not performing an aesthetic act. Note that Lopes's account doesn't claim that aesthetic value is final value or that aesthetic acts are disinterested. For example, if a painter puts the line there because it would make the painting aesthetically valuable, and they wanted to make the painting more aesthetically valuable for the sake of money, then they would still be engaged in an aesthetic act. Similarly, if they made a painting more aesthetically valuable in order for it to have political impact, they would still be engaged in an aesthetic act. What's crucial in the eBay example is that the painter there isn't taking aesthetic value into consideration at all. If we plug Lopes's account of aesthetic acts into the schema above, then we get the following: we trust in somebody's aesthetic sincerity when we rely on their commitment to act from their evaluations of aesthetic value. Obviously, somebody who had actually made those commitments, but who ignored aesthetic value in favor of, say, popularity, would be failing in their commitments.

Notice, too, the crucial difference between an artist who makes something aesthetically valuable for the sake of money, and an artist who simply makes something directly for the sake of money. In the former case, the artist is still constrained by their sense of value. Such an artist might be making a bid for popularity, but still be making art that they take to be good by their own aesthetic sensibility and sense of aesthetic value. We see such bids regularly. Consider, for example, Miles Davis's more popular works, like his very approachable cover of the Disney song "Someday My Prince Will Come", and indie director's Steven Soderbergh's more overtly popular works, such as Ocean's Eleven. These works are acceptable, I take it, because they still bear the imprints of their makers' aesthetic sensibility and values, even as they aim at creating a popular work within that sensibility. The true sellout is the artist who abandons their sense of aesthetic value, giving it up entirely in a bid for money or the like.

Crucially, trust in sincerity does not include trust in another's commitments to take care of our aesthetic interests, or to take our aesthetic needs into account. Trust in sincerity does not demand any sort of day-to-day reciprocal consideration, nor does the trusting person expect that the trusted person will intentionally cooperate with the truster in any of their particular actions. I can trust 
a narcissist to be true to themselves - and, in fact, I think this is what I am often doing when I trust artists and aesthetic interlocutors. My account here takes advantage of what is, to my mind, one of the most compelling aspects of Hawley's view. Her account makes no essential reference to any form of goodwill, nor to any intent to cooperate. I can trust people because I think they are committed to something; I do not need that commitment to make any reference to their care or regard for me. And I think this is characteristic of many of our aesthetic relationships.

\section{Aesthetic Sincerity and the Content of Trust}

In a moment, I'll say more about why I think trust in sincerity is so important to aesthetic life. But I'd like to step back for a moment and think about the nature of trust in general. The discussion of trust in aesthetic sincerity will, I think, have repercussions for the larger conversation about trust.

Consider a division within the recent literature on trust. On the one side, there's Hawley, whose account of trust involves no essential connection between trust and cooperativeness or other such kindly attitudes. On the other side are those theorists who think that trusting someone requires imputing some kind of sociable or kindly intent to them. The best-known example of such a view is Baier's account - that we trust others when we rely on their goodwill. As we've seen, the specifics of Baier's view have come under considerable fire. However, Karen Jones has developed an account in a similar spirit that avoids some of those problems.

Trust, says Jones, is an attitude aimed at tracking trustworthiness. Trustworthiness, in turn, is the disposition to be motivated by others' dependence on you. To be trustworthy is to be responsive to the needs of others. Says Jones, talk about trust and trustworthiness arises because humans are social, interdependent, and reflective. Our cooperative projects force us to depend on one another. But we are not simply inert with regard to those dependencies. We can respond to each other's dependencies; we can take the fact that others depend on us into account in our own actions. That is the way in which trustworthiness differs from mere reliability. The reliable person may act competently and well, but the trustworthy person actively adjusts their competent actions in light of others' dependencies on them. The trustworthy person, says Jones, takes the fact that others are counting on them as a motivation to act as counted on. Trustworthiness is the disposition to be motivated to actively fulfill another's dependency on you (Jones 2012: 62-66).

The trustworthy person is an active and reflectively self-aware participant in the practice of cooperation. So the trusting person can act with reflective 
awareness of the trustworthy person's reflective awareness. Thus, in Jones's account, the twin capacities of trust and trustworthiness enable a tightly bound, mutually aware, mutually reflective form of cooperation. We can do things together if we can depend on each other, and if we can know that the fact of our dependence will motivate each other to act.

This sort of direct mutual coordination is obviously present in many instances of trust: driving in traffic, going to the doctor, learning from a teacher. But I do not think such immediate forms of mutual coordination and such direct, reflective regard for others' dependencies is at the center of our trust practices with art. When I trust John Coltrane enough to pour hours of my attention into one of his extraordinarily difficult later albums, the content of my trust doesn't involve an expectation of his caring for me, or his being aware of and responsive towards my particular dependencies. I don't trust Coltrane to try to give us what we want or need. I trust Coltrane to make good music and be true to his musical sensibility - to make brilliant jazz guided by his own sense of how it should go. I trust him to be competent and sincere, and one can be competent and sincere without being directly and reflectively cooperative. The way for Coltrane to fulfill my dependencies on him is for him to, for the most part, forget about me and follow his own muse.

In other words: often an artist fulfills their social role, by, in an important sense, refusing to aim to fulfill the immediate dependencies of their audience. Notice the curious motivational structure here. I have suggested that the overall social structure of our artistic practice is designed to produce a large-scale coordination of efforts, but not one which will be achieved by individuals thinking about and responding to each others' needs in each particular moment. They coordinate with each other in the larger scheme of things by taking up commitments to largely ignore each others' needs in daily practice. Artists cooperate by pledging to be independent. ${ }^{20}$ And audiences typically pledge some analogous form of sincerity: they pledge to honestly report their perceived aesthetic value, rather than, say, praising the works of whichever artists need the most emotional support. (Though not all audiences. Your family members, for example, may support your work precisely because you need the emotional support, but that just reveals that the primary commitments there are familial rather than aesthetic.)

Think about when we feel deeply betrayed by artists and critics. We don't typically feel betrayed when a musician fails to make music for us. In fact, if they try too hard to make music to please us or to satisfy our pre-established sensibilities,

20. This comment modeled on my (2017b) discussion of how game-players can, in some circumstances, cooperate in producing a generally good time for all by submerging themselves in the attempt to compete with each other. 
we might think that they were pandering. We often feel most betrayed when an artist isn't true to their own aesthetic sensibility-when they have sold out to commercial interests, or just phoned it in out of laziness, or made an insincere bid for popularity. A paradigmatic form of indignation in aesthetic life is towards sellouts and other forms of aesthetic insincerity.

Of course, we don't feel betrayed when we think that they've broken their commitments for sufficiently good reason-as we are willing to forgive other breaches of commitments, given the right justification. And, of course, commitments to aesthetic sincerity aren't the only commitments in aesthetic life. Jazz musicians improvise together, and that improvisation is clearly ruled by a commitment to maintaining active cooperation. A friend promises to make me a mixtape to lift me out of my depressive funk; they have made a commitment to respond to my particular tastes and needs in the moment. And the commitments to aesthetic sincerity surely vary from one role to another. We would not, I take it, feel very betrayed if a member of city council recommended restaurants based on the restaurant owners' politics. Their role involves no commitment to aesthetic sincerity. But we would feel very much betrayed if it turned out that our newspaper's restaurant critic issued their recommendations on political grounds, for their role involves an implied commitment to aesthetic sincerity.

Let me note: there are also many cases of commitments to aesthetic steadfastness, and often there are very good reasons for making them. Such commitments can undergird efforts to build and maintain a healthy community, for one. In some cases, those commitments to steadfastness may be dominant, especially when the aesthetic practices are cornerstones in a community's life-most especially for vulnerable communities. We might, for example, expect to find such commitments to steadfastness around the linchpin cultural practices of threatened communities ${ }^{21}$ But it strikes me that, in much of contemporary art practice, trust in aesthetic sincerity is usually dominant.

The pervasiveness of trust in aesthetic sincerity can be glimpsed in its breach. Sellout cases are, I take it, paradigmatic cases of aesthetic betrayal, and usually give rise to the most morally loaded condemnations. Imagine, for instance, that an artist makes their artistic decisions based strictly on focus group data about what will sell well in upscale New York galleries. In that case, they have failed in their commitment to act from aesthetic considerations. They are not guided by their sense of aesthetic value, nor are they guided by any insight into which aesthetic properties will arise from non-aesthetic properties. Or, imagine a friend who makes book recommendations based on what will make them seem classy.

21. Relevant here is Matt Strohl and my discussion of how particular cultural practices can count as intimate to a group, and how that intimacy grounds cultural appropriation norms (Nguyen \& Strohl 2019). 
Again, they have failed to act out of aesthetic considerations, and we might reasonably feel that our trust has been betrayed.

On the other hand, we can be quite forgiving when we think that an artist has utterly failed to produce good art, if the attempt was sincere. The wild overreach, the failed aesthetic experiment-these don't provoke accusations of betrayal. Notice, however, that our reactions here are quite complex and variable. For example, we seem far more forgiving of aesthetic insincerity when the results are aesthetically competent. (Sometimes I point out to people that much of seventies R\&B, like Earth Wind and Fire, was entirely stage-managed by record companies for popularity and profit, to which the response is usually: "Yeah, but it's good.") This variability, I suspect, is due to complex varying interactions between the twin commitments to competence and sincerity. Our reactions to a failure to fulfill one commitment is often moderated by the fulfillment of the other. We often forgive the insincere but good, and also forgive the failed but sincere. The situation is made more complex by significant variances in between different aesthetic communities. I suspect that most pop music listeners are far more interested in competence than sincerity, as evidenced by the relatively greater degree of anger and betrayal at incompetent music, and the relative lack of betrayal at revelations of profit motives in the artists. On the other hand, most avant-garde artistic communities seem marked by much trust in aesthetic sincerity and relatively little trust in aesthetic competence. Though audiences for avant-garde art are still interested in aesthetically successful works, they don't seem to treat each other as committed to, and culpable for failures at, aesthetic competence. They do, however, seem to treat each other as beholden to commitments to aesthetic sincerity.

Let's return to Kanye West. In Geavey's criticism, her sense of betrayal towards West seems rooted in a very specific complaint. She is accusing West of being aesthetically lazy. She condemns his work, not simply for being bad, but for being "half-hearted." (It would be a very different criticism to say that he had "lost his touch," and I rather suspect that such a criticism would probably not have been accompanied with such vitriolic condemnation.) I take aesthetic laziness to be a complex mixture of failures of competence and sincerity. The work is bad, one might think, precisely because West had failed to be sufficiently motivated by aesthetic considerations to put in the requisite amount of effort. The sense of betrayal here is grounded, not in the works' mere badness, but in how the badness arose from West's motivational state. He failed to be properly motivated by his apprehension of aesthetic value.

Notice, too, that different forms of sincerity can come into play, depending on the details of the exact aesthetic role and the particular relationship. We trust the curator or the interior decorator to be true to what they think is aesthetically valuable from some kind of objective (or at least more socially generalized) 
standpoint, and to downplay their own personal aesthetic sensibility. But when we argue with friends about great movies, we trust them to be true to their own personal sensibility. The same goes for artists. I don't trust West simply to put out music that he has good reason to think is aesthetically valuable-I trust him to put out the kind of music that emanates from his own particular aesthetic loves and passions, from his peculiar sense of how his music should be. ${ }^{22}$

It should be clear now that the commitment here isn't the sort that demands direct, immediately self-aware cooperation. This gives us a significant reason to prefer Hawley's minimal account over accounts like Jones's, which build a thoroughgoing, constant, and explicit mutuality into the very essence of trust. Hawley's account only specifies that there be a commitment; it does not specify that that commitment have any content of sociality, interpersonal care, or responsiveness. That is, one may take up the commitment for a social reason, but the content of the commitment is independent action. With aesthetic sincerity, we commit for the sake of cooperation, but we do not commit to cooperate.

Crucially, in Hawley's account, when I trust somebody to meet their commitments, I don't necessarily trust that they will do so from their motivation to keep those commitments. You might commit to cleaning the house, and I might trust you to fulfill your commitment because you are a neat freak and you just won't be able to help yourself. Similarly, an artist might acquire a commitment to be sincere by occupying the social role, and then fulfill it out of their utter absorption in their own aesthetic interests. In that case, we are still coherently trusting them, and they are still coherently fulfilling our trust. ${ }^{23}$

22. One might, furthermore, think that we ask of artists something narrower than staying true to their own personal aesthetic sensibility - to act out of their artistic style. Nick Riggle has suggested that artistic style is a narrower category than sensibility, since it involves not only what the artist likes, but their personal ideal for their own artistic production (Riggle 2015).

23. There is a complexity here worth exploring further. My analysis implies the following possibility: a role may be designed for the sake of sake of social coordination, with certain commitments built in. A person may step into that role because they think the commitments fit their character, or for other incentives attached to the role-even if that person lacks any personal interest in social coordination. The commitments have been designed or have evolved for the sake of social coordination, and the incentives may be attached to the role to promote social coordination, but the particular person fulfilling the role doesn't share those interests. (To take an unusually explicit and clear example: a lawyer's professional commitments may be designed to play a particular social function, but many individual lawyers may not have interest in those functions; they merely adopt the package for the financial incentives.) In that case, I think we should still say the commitments are there for the sake of coordination, even if the individual taking them up doesn't take them up for the sake of coordination. I suspect that, when we start to think more about the social design of roles and their associated commitments, we will find many this to be a common structure. (For those who worry about my reference to the possibility of an unintended, but evolved function. see A. W. Eaton's [2020] useful discussion of how artifacts may evolve functions separately from the intentions of their designers. I am suggesting that social roles be a form of artifact, with an evolved function. I plan to explore this possibility further in future work.) 
Consider Marianne Moore, whose poetry springs forth with a truly idiosyncratic rhythm and pattern of intellect. As the story goes, when Moore would occasionally try to sound like other poets, she would fail utterly. She could not even come up with the most mundane and commonplace of nursery rhymes. Here is the poet Elizabeth Bishop's description of Moore, her mentor:

For my own amusement, I had already made up a completely unscientific theory that Marianne was possessed of a unique and involuntary sense of rhythm, therefore of meter, quite unlike anyone else's. She looked like no one else; she talked like no one else; her poems showed a mind not much like anyone else's; and her notions of metering rhyme were unlike all the conventional notions-so why not believe that the old English meters that still seem natural to most of us (or seemed to, at any rate) were not natural to her at all? (Bishop 1984: 139-40)

The essay from which this quotation is taken, "Efforts of Affection: A Memoir of Marianne Moore," is an ode of aesthetic love for Moore, for whom Bishop expresses enormous affection, and in whom Bishop places extraordinary aesthetic trust. And at the center of the portrait is a picture of Moore as entirely and wonderfully aesthetically inflexible. Moore cannot help her idiosyncrasy and originality. But note that Jones's picture of trust is essentially one of flexibility. Trustworthiness, in Jones's picture, is essentially the disposition to change one's actions in light of another's dependence on one. For Jones, the practice of trust involves adjusting ourselves to fit each other's needs. But Bishop trusts Moore's art, Moore's advice about how to grow as a poet, and Moore's recommendations, precisely because Moore's art and aesthetic talk spring from an overwhelming staunchness of character. Bishop trusts Moore precisely because Moore will always be honest and unyielding in her loyalty to her own aesthetic sensibility.

Many of the more traditional, cooperation-centric views of trust might now seem a bit narrow. Let me offer a diagnosis of that narrowness. The philosophical discussion about trust on which I've focused has, historically, come from thinking about ethics. ${ }^{24}$ And the narrower analysis of trust is often correct for the moral domain. In moral life, trust does usually involve relying on each other's commitment to cooperation, coordination, and reflective mutuality. In moral life, we do actively adjust to each other's needs in order to get along. But in aesthetic life, we often trust, not those who have goodwill or who are considerate of our needs, but those who are aesthetically sincere. And sincerity can sometimes

24. Another significant conversation on the nature of trust has emerged in the literature of the epistemology of testimony. I leave that discussion aside for the moment, for brevity's sake, since it often leaves the normative dimension to the side. Trusting expert testimony may be more a matter of reliability than of a richer, more normatively loaded form of trust. 
take the form of delightful inflexibility, which we treasure in the aesthetic sphere in a way that we do not in the moral sphere.

Notice that we can specify aesthetic sincerity at differing levels of stringency. In weak sincerity, the requirement is for acting out of aesthetic considerations one accepts. In strong sincerity, the requirement is for acting out of aesthetic considerations one has grasped or understood for oneself. For example, imagine a head museum curator who, though sensitive to many eras of art, happens to have no feeling for Rococo art. When selecting artwork for the Rococo room in their museum, they rely on the testimony of Rococo experts as to what is aesthetically valuable. ${ }^{25}$ The museum curator fulfills the conditions of weak sincerity, since they are selecting work because they believe it to be aesthetically valuable, rather than for its popularity or its investment value. They are consulting expert specialists on the aesthetic value of Rococo, rather than experts on market research. However, the museum curator does not fulfill the conditions of strong sincerity, because they do not grasp that aesthetic value through their own experience or understanding.

It seems, from canvassing our affective responses, that different social roles in the art world carry differently stringent commitments to sincerity. We seem to take solo musicians, painters, and novelists to have commitments to strong sincerity, as well as our aesthetic interlocutors. But museum curators, actors, and orchestra members we take only to have a commitment to weak sincerity, since we are not betrayed by the fact that they are following somebody else's leadperhaps even entirely subsuming themselves to another's particular aesthetic sensibility. Notice, however, that we do still demand that they try to be responsive to aesthetic considerations, albeit via testimony. When I trust a museum curator to be weakly sincere, I am trusting them to be looking for experts who are themselves strongly sincere. The actor may not understand exactly why they are supposed to deliver their line reading with a hint of terror, but they do so because their director tells them to. They may not grasp the particular aesthetic consideration directly. But they are still weakly aesthetically sincere insofar as they are obeying their director because they trust their director's direct grasp of the aesthetic considerations.

Interestingly, this gives us a different way to look at some earlier debates about testimony. Many have claimed that one ought not make an aesthetic judgment without having the requisite experience for oneself. Some have claimed that this might be a norm that arises specifically from the practice of assertion (Robson 2015; Ransom 2017). But if what I've suggested is right, then the norms around aesthetic testimony are part of a larger practice, in which we demand sincerity across a broad range of aesthetic actions, beyond testimony.

25. Example adapted from Nguyen (2017a). 
In any case, we have learned something significant about the nature of trust across a broad swath of human activities. Accounts like Jones's, which require that the trustworthy person be actively motivated by their understanding of others' dependencies, seem to describe a version of trust suited to distinctively moral activity. But those accounts founder when we consider trust in aesthetic sincerity. The right account to capture both the moral and aesthetic forms of trust is Hawley's. It seems plausible that the content of those commitments have something like a Jonesian form in the moral sphere-that they are commitments to act out of an awareness of others' dependencies. But the characteristic form of trust in artistic life aims at a commitment to sincerity. I trust Kanye West, but I don't for a moment think that he cares about fulfilling my needs. I trust him to care about his music - single-mindedly, possibly to his moral detriment and the harm of those around him. In fact, the character traits underlying his moral flaws might be part of the very reason that I trust him so much aesthetically.

\section{Why Commitments in Art?}

Why think that our relationship to each other is one of trust, rather than merely one of reliance? That is, why think that we aren't simply relying on each other's predictable behavior, but that we are making and fulfilling commitments? I have argued that we do, in fact, have the affective responses of betrayal, and that the presence of these responses indicates that we take ourselves to be operating in the space of commitment and trust. But the more interesting question is the justificatory one: What value might we get from the practices of committing and trusting in our life with art? What functions might they serve?

Earlier, I suggested that trust in aesthetic competence was what got us over the hump, motivating us to put in the effort with difficult art. One might have, at that moment, protested that mere reliance in aesthetic competence could play some of that function. After all, I only need to have some predictive reason to think that Kanye's next album will be good, in order to spend my effort on it. Why bring trust into the matter?

The answer should be quite familiar. We involve trust when we bring in commitments, and we bring in commitments when we are attempting to actively structure practices of intentional cooperation. In artistic life, audiences do not simply treat artists merely as reliable mechanisms for creating good art, and artists do not treat audiences as mere reliable mechanisms for paying attention. Artist and audience actively coordinate. This is clearest in cases of difficult art. The practice of developing, making, and appreciating difficult art is greatly aided by the existence of intentional social coordination. The artist makes difficult art in part because they know that an audience has committed to putting 
in the effort to understand it. And the audience puts in the effort partly because they know the artist has committed to making good art. Here, as elsewhere in social life, commitments are the grease that enables more complex and entangled cooperative endeavors. Of course, one could, technically, imagine artists making and audiences appreciating difficult art without a structure of commitments in place, just as would could, technically, imagine a group of people cooking, living, and working together without a structure of commitments in place. But it hardly seems possible in real life social circumstances. In most human endeavors, we need commitments in order to enable more complex and efficient forms of cooperation.

Contemporary aesthetics sometimes misses the importance of social coordination because it is often focuses narrowly on analyzing solitary encounters between an appreciator and a work. But the need for social coordination in aesthetic life becomes evident when we step back and think about the long-term choices and relationships of aesthetic agents, especially when embedded within aesthetic communities. Think, for example, of the social relationships underpinning the development of musical styles. Jazz musicians become specialists because they expect an audience to pay attention-and to provide financial and emotional support. Jazz fans invest their energy into developing their jazzlistening skills and sensitivities because they trust jazz musicians to keep making more interesting jazz. We need those commitments to underwrite the efforts we put into making new art, developing the sensibility to appreciate it, and writing articles to untangle what it's all about.

But though this answer surely captures some of the truth, it does not explain all of the phenomena. For if this were the complete story, the content of our commitments would need to only involve commitments to steadfastness and competence, and not to sincerity. We would simply need to commit to, say, developing some particular style or genre together. But the pattern of our affective responses seems to indicate, instead, that we have a particularly emphatic interest in sincerity. What might justify the practice of asking for and making commitments to aesthetic sincerity? Why might we want such an emphasis on aesthetic sincerity in our aesthetic social practice?

Let me propose two different answers to that question, which I think will intersect in fruitful ways. The first possibility is that a social practice centered on sincerity would encourage originality. We don't only want more jazz music like what we already have. We value change, innovation, and novelty. And a commitment to aesthetic sincerity, rather than to steadfastness or competence, is a good way to promote those interests. We want artists to abandon old styles and shift to new ones; we want curators to get excited by new artistic movements and spotlight them. We want our friends to evolve their tastes and urge new delights on us. We want critics to reach for new interpretations, to surprise us with their 
innovative takes. This is distinctive of the artistic domain over the moral domain. In moral life, I mostly just want people to stay in their lanes. If the world were already replete with moral goodness, we might have no further interest in moral innovation. But many of us do want an artistic world full of lane-changing, category-breaking unpredictability. And, despite the fact that the world is already chock-full of good art already-more than we could possibly experience in our short lives, in fact-most of us still value further artistic innovation.

Imagine, for a moment, that we asked all the members of the art world to commit to being steadfast to some particular aesthetic style or sensibility. Bop jazz people should stay steadfast to the sensibilities of bop jazz, doom metal people should stay true to doom metal. Commitments to steadfastness offer the simplest solution to the coordination problem for difficult art. They would guarantee that the audience will put in the effort to a given type of art, and that new instances will likely be, at least, within the specified sensibility. But commitments to steadfastness won't help us achieve other key aesthetic values. By themselves, they offer no reason to think that that coordination will produce good art, nor original art.

We could commit, instead, to aesthetic competence. But while that might help us foster good art, that commitment by itself won't help us get original art. It may, in fact, suppress originality. Art, when it is creative, is unpredictable; creative artists cannot fully control the success of their output, no matter how hard they try. But if artists were to obey a dominant commitment to competence, they would have reason to avoid originality and stick to well-hewn aesthetic pathways, where success was more assured. If artists took themselves to have a dominant commitment to artistic competence, then they would have reason to create conservatively. But if they also took themselves to have some significant commitment to sincerity, they might be more willing to take risks when their aesthetic sensibility pointed that way. When we are interested in fostering a vital, ever-changing, innovative aesthetic community, full of good and original art, then the best strategy seems to be for us to take on commitments both to aesthetic competence and aesthetic sincerity. And the greater our interest in originality, then the greater the emphasis we should put on the commitment to aesthetic sincerity.

On the other hand, in traditionalist aesthetic cultures, it is more reasonable to expect and demand aesthetic success on the regular. So we should expect the relative degree of our expected commitments to sincerity and competence to vary between different aesthetic communities, depending on their relative interests. This is why, I think, we find relatively great emphasis on aesthetic sincerity in avant-garde art communities. And it is why we find the strongest commitments to steadfastness and competence in traditionalist aesthetic communities-like, say, the one around traditional Japanese cuisine. 
Sincerity seems particularly important here because creativity, innovation, and originality are likely self-effacing as ends. What do I mean? A self-effacing end is one which cannot be achieved through direct pursuit. The pleasures of love, for example, are self-effacing. I cannot get the pleasures of love through direct pursuit. If I tried to love somebody else just for the sake of getting the pleasures of love for myself, then I would inevitably fail, for such self-interested action wouldn't really be love. I have to love another person for their own sake in order to obtain the particular pleasures of love. ${ }^{26}$ Let's now introduce a social variant of the concept. Let's call something a "socially self-effacing end" if it is an end I can achieve with the help of others, but not by directly asking them to help me to achieve it. Suppose that I depend on a network of artists, curators, critics, and recommenders to satisfy my interests for good art, where some of that goodness lies in its originality. In that case, it may be best for the various aesthetic agents not to act from a constant awareness of my dependency. In order to fulfill the particular form of dependency I have with them, it might be best for them to ignore my interests completely and follow their own sense of aesthetic value wherever it might lead. Why? The answer may simply be a matter of empirical psychology. Excess concern with the audience's reception seems, for many artistic psychologies, to dim the capacity for creativity. Artistic creativity seems to flourish under conditions of single-mindedness and even narcissism. ${ }^{27}$

In the moral domain, I want others to acknowledge my dependencies on them; I want others to keep my needs in mind. But in the aesthetic domain, if the ends involved are truly socially self-effacing, then the best way to get what we want out of each other is to ask each other to ignore our explicit interdependencies and to try to follow our own, ever-shifting internal muses. This is also why we might prefer a commitment to aesthetic sincerity, rather than a commitment to aesthetic novelty. The commitment to aesthetic sincerity emphasizes the artist's loyalty to their own sensibility, and actively encourages them to ignore their audience in a way that a mere commitment to aesthetic novelty would not. After all, the attempt to be novel for novelty's sake can also be pandering.

Artists, critics, and appreciators often do wander mightily when they follow their aesthetic muses. Miles Davis switches from hard bop to modal jazz, and then again to jazz-rock fusion. Alan Moore abandons the school of gritty cynicism about superheroes that he helped to create with Watchmen, and goes for an over-the-top four-color optimistic style with Top 10 and Tom Strong. Bob Dylan goes electric. The same can happen with critics and curators. Lester Bangs, early

26. I am adapting here on the literature on self-effacing ends-that is, ends that cannot be pursued directly. The language of "self-effacingness" was introduced by Derek Parfit (1984: 23-24). Recent discussion has also included Keller (2007), Annas (2008), Hurka (2000), Pettigrove (2011: 192-93).

27. Kieran (2018) summarizes past research on this topic. 
punk critic and extreme punk loyalist, turned against punk in his later years and wrote of his great love for the disco and prog-rock sounds of Roxy Music. In these cases, it seems like the practitioner is ignoring the dependencies of their audience-at least the most obvious and immediate dependencies. The artist seems to not be giving their audience what they've asked for.

But why aesthetic sincerity, rather than just sincerity, full stop? Aesthetic sincerity, at least, narrows the domain. In practices where we pursue originality, there can be no guarantee that an artist will find an audience, or that audiences will find art to their liking. But that is the cost of engaging in any deeply unpredictable creative endeavor. The best we can do is to collectively adopt commitments to aesthetic sincerity - to promise each other to be guided by our sense of aesthetic value. We cannot coordinate on a specific aesthetic result, if our interest is in finding new results, but we can coordinate on staying together within the realm of the aesthetic.

This gives us a fuller explanation of why we'd want our coordination to involve a significant commitment to aesthetic sincerity, with all the peculiar independence that implies. On the one hand, if we didn't have any sort of commitments at all, we wouldn't be able to achieve the long-term goods of coordination. On the other hand, if we had commitments to immediate responsiveness to each other's dependencies, we wouldn't be able to pursue the goods of originality as effectively. What we can find is a middle ground: a long-term commitment to aesthetic sincerity that leads us into the same arena, but which also encourages to take our own paths within that arena. Commitments to aesthetic sincerity, specifically, encourage individualistic action, while compressing it within a particular domain of interest, and so making sincere convergences more likely. Thus, commitments to aesthetic sincerity are the right tool for supporting the communal pursuit of originality. Notice that we can also add further commitments to steadfastness here, which would further compress the domain of interest. This would make convergences more likely, at the cost of making verboten many forms of originality. Again, some aesthetic communities seem willing to pay that price, and others not.

Let's now turn to the second explanation for the commitment to sinceritythat sincerity supports the value of aesthetic community. (The explanation from community can function independently from the explanation from originality, though they are also compatible). Suppose that you and I happen to share some aesthetic connection. Perhaps you made an artwork and I adore it. Or perhaps we are both fans of the same music-perhaps we even discover that we share an inexplicable love for the same odd, fascinating moments of jarring tempo shifts. The fact that we share that very specific love may itself be valuable. The value of that sharing may take several forms. As Ted Cohen puts it, in a somewhat Kantian mood, some art can be shared universally and so lead to a sense of the 
connection we have to humanity as a whole. Other art we may share with a limited number, and through it find intimacy within small communities (Cohen 1993). Discovering a shared love for some particular piece of art reveals something about our connection to each other-about the similarity of our sensibility, our sensitivity, our responsiveness.

But notice that our sharing here is an exciting discovery only if we arrived at it through the independent application of our own sensibilities. If, on the other hand, our sharing were merely to arise as an explicit solution to a coordination problem, then we would have learned very little about the similarity between our distinctive sensibilities. We would have learned, at most, about our cooperative intent. The fact that everybody in America drives on the right side of the road is no miracle, nor does it reveal any special nature shared by all Americans. It reveals only that we are attempting to live in a society of drivers together, and have settled upon one arbitrary solution in order to get along. On the other hand, it always strikes me as something of a miracle when I run across somebody that shares one of my more esoteric tastes, like for Thelonious Monk's wild cover of "Smoke Gets in Your Eyes", or for Madoka Magica, a particularly mind-bending and narratively perverse bit of Japanese anime. But it strikes me so precisely because the sharing was not pre-arranged. The sense of a miraculous discovery only comes about if we have navigated to it by our own lights. Otherwise, it would not be a discovery about our shared nature.

Asking that our primary commitment be to steadfastness would actually undermine the possibility of such discoveries. Under a commitment to steadfastness, any convergences would best be explained as the result of explicit coordination, rather than in terms of some uncovered similarity between independent beings. Commitments to steadfastness would make sense if we cared most about our aesthetic choices as voluntary expressions of our solidarity with one another, and as symbols of our willingness to change ourselves to fit one another. (And, that is what some aesthetic communities care about, and I think, in those communities, we do often find steadfastness to be the dominant commitment.)

But we can support the discovery of a shared nature by encouraging the independent and sincere exploration of particular shared domains. If we value the discovery of convergence between independently-minded actors, then we should build a degree of day-to-day uncooperativeness into the relevant social practice. The demand for sincerity, then, can be explained by our interest in discovering a shared nature, rather than our interest in enforced coordination. ${ }^{28}$

28. If this explanation is to work, then we should expect that we demand strong sincerity in general, and that those cases of weak sincerity we accept arise in special contexts, and usually involve parasitism on somebody else's strong sincerity. I think this is, in fact, what we find. 
And this helps us to towards understanding why the demand for sincerity sits so comfortably with the demand for competence. They mirror the twin goals of the aesthetic social practice. The point here is that aesthetic life is not about sharing just any old thing; it is about sharing our appreciation of works that are good. In our aesthetic practice, we seem to want both to encounter aesthetically valuable work, in and of itself, and to connect with each other over our experiences of aesthetically valuable works. The social function rides on top of the value of independent encounters with aesthetically valuable objects. We want to find beautiful things worth appreciating that seem made just for our sensibilities and to discover, in the process, that other people had precisely that same experience of value and fit. After all, if we just wanted to share something-anything at all-we wouldn't have such a delightful and surprising discovery of connection. It is precisely that we are each independently going about, looking for things that sincerely appeal to our peculiar sensibilities, that it is so especially striking when we discover that what delights also delights another. In our aesthetic life, we seem to value discovering a harmony between our individualities. ${ }^{29}$

This is a kind of communal connection that, I take it, would be largely impossible to seek in the moral sphere-most especially, in the regulated social and legal sphere. Our overpowering need to enforce coordination in those spheres makes it relatively unlikely that we will have many such spontaneous free convergences. But our life with art is different. There, we value creativity, but we also value our convergences through that creativity. But that value can only be fostered when we encourage individuality. And we can take the risk of non-convergence in aesthetic life precisely because the terrain is relatively skew to our basic needs and core social freedoms. And when we take that risk - when we permit independence through commitments to sincerity, rather than enforced coordination - we court a very special reward. This is why, I think, the commitment to sincerity is so distinctive of the aesthetic domain, and why it is often more important that we nurture it there. We need to make more explicit commitments to paying attention to and responding to each others' dependencies in the moral and social spheres. But in the aesthetic sphere, we can take risks. We can encourage each other to each follow our own peculiar sensibilities, for the hope of finding that special connection-because we will survive if fail to find such unexpected harmony. We can take no such risk with, say, the rules of driving.

And this is why the particular form of aesthetic trust is so distinctive from that of moral trust. Aesthetic life is where we ask each other to make the particular commitment to be true to ourselves. The forces which pull away from

29. Though the idea of "harmony in individuality" obviously has Kantian roots, I am most influenced by the recent articulation Nick Riggle (2017) has given to this idea. 
sincerity - to pander, to do market research, to sell-out-are so strong and the compensations so vivid. But giving in to such motivations would undermine the shared leap of aesthetic life. I learn of no special connection in our natures, when you changed your artistic style just to pander to my taste, or because you did focus groups on my cultural cohort's preferences. A commitment to sincerity helps underwrite the genuineness of our aesthetic convergences. In aesthetic life, we trust each other to each follow our own paths, so that it is more meaningful when we do cross paths.

\section{Acknowledgments}

I'd like to thank, for all their wise and kind assistance, Anthony Cross, Adrian Currie, John Dyck, Jonathan Gingerich, Keren Gorodeisky, Samantha Matherne, Aaron Meskin, Erich Matthes, Nick Riggle, and the editors and referees of Ergo.

\section{References}

Annas, Julia (2008). Virtue Ethics and the Charge of Egoism. In Paul Bloomfield (Ed.), Morality and Self-Interest (205-21). Oxford University Press.

Baier, Annette (1986). Trust and Anti-Trust. Ethics, 96(2), 231-60.

Bishop, Elizabeth (1984). The Collected Prose. Farrar, Straus and Giroux.

Budd, Malcolm (2003). The Acquaintance Principle. The British Journal of Aesthetics, 43(4), 386-92.

Cohen, Ted (1993). High and Low Thinking about High and Low Art. The Journal of Aesthetics and Art Criticism, 51(2), 151-56.

Cross, Anthony (2017). Art Criticism as Practical Reasoning. British Journal of Aesthetics, 57(3), 299-317.

Eaton, A. W. (2020). Artifacts and Their Functions. In Ivan Gaskell and Sarah Anne Carter (Eds.), Oxford Handbook of History and Material Culture (35-53). Oxford University Press.

Fricker, Miranda (2007). Epistemic Injustice: Power and the Ethics of Knowing. Oxford University Press.

Goldberg, Sanford (2010). Relying on Others: An Essay in Epistemology. Oxford University Press.

Hawley, Katherine (2014). Trust, Distrust and Commitment. Noûs, 48(1), 1-20.

Holton, Richard (1994). Deciding to Trust, Coming to Believe. Australasian Journal of Philosophy, 72, 63-76.

Hopkins, Robert (2001). Kant, Quasi-Realism, and the Autonomy of Aesthetic Judgment. European Journal of Philosophy, 9(2), 166-89.

Hopkins, Robert (2011). How to Be a Pessimist about Aesthetic Testimony. Journal of Philosophy, 108(3), 138-57.

Hurka, Thomas (2000). Virtue, Vice, and Value. Oxford University Press. 
Irvin, Sherri (2007). Forgery and the Corruption of Aesthetic Understanding. Canadian Journal of Philosophy, 37(2), 283-304.

Jones, Karen (1996). Trust as an Affective Attitude. Ethics, 107, 4-25.

Jones, Karen (2012). Trustworthiness. Ethics, 123(1), 61-85.

Keller, Simon (2007). Virtue Ethics Is Self-Effacing. Australasian Journal of Philosophy, $85(2), 221-31$.

Kieran, Matthew (2018). Creativity, Vanity, and Narcissism. In Berys Gaut and Matthew Kieran (Eds.), Creativity and Philosophy (74-92). Routledge.

Kitcher, Philip (1993). The Advancement of Science. Oxford University Press.

Laetz, Brian (2008). A Modest Defense of Aesthetic Testimony. The Journal of Aesthetics and Art Criticism, 66(4), 355-63.

Lena, Jennifer C. (2012). Banding Together: How Communities Create Genres in Popular Music. Princeton University Press.

Livingston, Paisley (2003). On an Apparent Truism in Aesthetics. British Journal of Aesthetics, 43(3), 260-78.

Lopes, Dominic McIver (2011). The Myth of (Non-Aesthetic) Artistic Value. The Philosophical Quarterly, 61(244), 518-36.

Lopes, Dominic McIver (2019). Being for Beauty: Aesthetic Agency and Value. Oxford University Press

Lord, Errol (2016). On the Rational Power of Aesthetic Testimony. British Journal of Aesthetics, 56(1), 1-13.

McKinnon, Rachel (2017). How to Be an Optimist about Aesthetic Testimony. Episteme, 14(2), 177-96.

Meskin, Aaron (2004). Aesthetic Testimony: What Can We Learn from Others about Beauty and Art? Philosophy and Phenomenological Research, 69(1), 65-91.

Meskin, Aaron (2007). Solving the Puzzle of Aesthetic Testimony. In Matthew Kieran and Dominic McIver Lopes (Eds.), Knowing Art (109-24). Springer.

Nguyen, C. Thi (2017a). The Uses of Aesthetic Testimony. The British Journal of Aesthetics, 57(1), 19-36.

Nguyen, C. Thi (2017b). Competition as Cooperation. Journal of the Philosophy of Sport, 44(1), 123-37.

Nguyen, C. Thi (2018). Echo Chambers and Epistemic Bubbles. Episteme, 17(2), 141-61. https://doi.org/10.1017/epi.2018.32

Nguyen, C. Thi (2019). Autonomy and Aesthetic Engagement. Mind, 129(516), 1127-56. https://doi.org/10.1093/mind/fzz054

Nguyen, C. Thi (2020). Cognitive Islands and Runaway Echo Chambers: Problems for Expert Dependence. Synthese, 197(7), 2803-21. https://doi.org/10.1007/ S11229-018-1692-0

Nguyen, C. Thi (in press). Trust as an Unquestioning Attitude. Oxford Studies in Epistemology.

Nguyen, C. Thi and Matt Strohl (2019). Cultural Appropriation and the Intimacy of Groups. Philosophical Studies, 176(4). 981-1002.

O'Neill, Onara (2002). Autonomy and Trust in Bioethics. Cambridge University Press.

Parfit, Derek (1984). Reasons and Persons. Oxford University Press.

Pettigrove, Glen (2011). Is Virtue Ethics Self-Effacing? The Journal of Ethics, 15(3), 191-207.

Ransom, Madeleine (2017). Frauds, Posers, and Sheep: A Virtue Theoretic Solution to the Acquaintance Debate. Philosophy and Phenomenological Research. Advance online publication. https://doi.org/10.1111/phpr.12467 
Riggle, Nick (2015). Personal Style and Artistic Style. The Philosophical Quarterly, 65(261), 711-31.

Riggle, Nick (2017). On Being Awesome: A Unified Theory of How Not to Suck. Penguin Books.

Robson, Jon (2015). Norms of Belief and Norms of Assertion in Aesthetics. Philosopher's Imprint, 15(6), 1-19.

Simpson, Thomas (2012). What Is Trust? Pacific Philosophical Quarterly 93: 550-569.

Simpson, Thomas (2018). Trust, Belief, and the Second-Personal. Australasian Journal of Philosophy 96 (3): 447-459.

Whiting, Daniel (2015). The Glass is Half Empty: A New Argument for Pessimism about Aesthetic Testimony. The British Journal of Aesthetics 55 (1): 91-107. 